\title{
How long is the yardstick for smoking bans in Switzerland?
}

\author{
Martin Röösli · Sarah Rajkumar
}

Published online: 2 October 2013

(c) Swiss School of Public Health 2013

In the mid-eighties, Switzerland was one of the first countries worldwide admitting to the public health burden of ambient air pollution and thus initiating rigorous measures to reduce air pollution levels. For instance, in 1986 Switzerland was the first country in Europe to introduce compulsory catalysers for new cars. As a consequence, levels of ambient air pollution such as sulphur dioxide $\left(\mathrm{SO}_{2}\right)$, nitrogen dioxide $\left(\mathrm{NO}_{2}\right)$ and particulate matter (e.g., $\mathrm{PM}_{10}$ ) noticeably decreased in the nineties. This striking public health success story resulted in observable health benefits like a decline in respiratory symptoms in children (Bayer-Oglesby et al. 2005) or lung function improvements in adults (Schikowski et al. 2013). Since 2000 the decrease of $\mathrm{NO}_{2}$ and $\mathrm{PM}_{10}$ has slowed down and nowadays typical annual Swiss $\mathrm{PM}_{10}$ averages range between $14 \mu \mathrm{g} / \mathrm{m}^{3}$ in rural background sites and $24 \mu \mathrm{g} / \mathrm{m}^{3}$ in the proximity of traffic (Federal Office for the Environment FOEN 2013). Apparently, today a further reduction of air pollution levels needs more elaborate and cost-intensive efforts than before and such measures are partly counterbalanced by the increasing number of cars as well as other sources. The question thereby arises which other low hanging fruits are ready to be harvested to further reduce the population's exposure to fine particles.

An obvious candidate is environmental tobacco smoke (ETS). In terms of ETS, however, Switzerland is far away from a success story. The WHO Framework Convention on

M. Röösli (ه) · S. Rajkumar

Epidemiology and Public Health Department,

Swiss Tropical and Public Health Institute, Basel, Switzerland

e-mail: martin.roosli@unibas.ch

URL: http://www.swisstph.ch

M. Röösli · S. Rajkumar

University of Basel, Basel, Switzerland
Tobacco Control has still not been ratified. By 2006, smoking restrictions in public places were rare (Friedrich et al. 2009) and associated health costs were estimated at 419 million Swiss Francs (Hauri et al. 2011). In May 2010, after controversial debates, a Federal ban was introduced in public places but the regulation leaves room for a lot of exceptions in hospitality venues. The loosely interpreted rules leave ETS exposure at public places like railway stations or in entrance areas still common nowadays. In a representative survey that was conducted after the Federal smoking ban introduction among individuals between 14 and 65 years of age, $10 \%$ still reported exposure to ETS for at least $1 \mathrm{~h} /$ day and $58 \%$ for at least $1 \mathrm{~h} /$ week (Krebs 2011). It can easily be calculated that this has a considerable impact on the overall fine particulate exposure. Measured average PM2.5 levels range between 150 and $200 \mu \mathrm{g} / \mathrm{m}^{3}$ in smoking areas of hospitality venues and between 50 and $100 \mu \mathrm{g} / \mathrm{m}^{3}$ in adjoining non-smoking areas (Huss et al. 2010). Spending $1 \mathrm{~h} /$ day at a concentration level of $100 \mu \mathrm{g} / \mathrm{m}^{3}$ corresponds to an average ambient PM2.5 concentration of $4 \mu \mathrm{g} / \mathrm{m}^{3}$, which corresponds to the population weighted average exposure to traffic-related PM10 concentration in Switzerland (Sommer et al. 2008).

Obviously, personal PM2.5 exposure is much higher for hospitality workers who are forced to spend much more time in highly polluted areas. Their average ETS exposure is estimated to correspond to the consumption of $2-3$ cigarettes per day (Rajkumar et al. 2013).

For the benefit of the population's health (U.S. Department of Health and Human Services 2006; Röösli 2011) ETS exposure in the daily environment needs to be further minimized. The supporting evidence is clear and beyond doubt. A common exposure-response function for fine particles from tobacco smoke and ambient air pollution has been demonstrated (Pope et al. 2011). Acceptance of 
smoking bans is increasing all over the world (Lazuras et al. 2012; Usmanova and Mokdad 2013) even in smokers (Moore et al. 2012). However, inconsistent and heterogeneous rules such as the ones implemented in Switzerland lessen the acceptance (Hyland et al. 2009). In addition, they are ineffective when it comes to exposure minimization (Lopez 2010) and generate never ending public debates including new initiatives to further weaken existing laws. Negative economic consequences, as often brought up by opponents (Halpern and Taylor 2009), could neither be observed in a Swiss region with a comprehensive smoking ban (Schulz et al. 2012) nor be confirmed in comprehensive reviews (Fromme et al. 2009). Strict rules have a positive impact on the smoking behaviour, particularly in adolescents (Chuang and Huang 2012), leading to further public health benefits. Thus, for Switzerland it is time to measure ETS exposure with the same yardstick as ambient air pollution exposure and take rigorous measures to reduce exposure to ETS in the daily environment.

\section{References}

Bayer-Oglesby L, Grize L, Gassner M, Takken-Sahli K, Sennhauser FH, Neu U, Schindler C, Braun-Fahrlander C (2005) Decline of ambient air pollution levels and improved respiratory health in Swiss children. Environ Health Persp 113(11):1632-1637

Chuang SH, Huang SL (2012) Changes in smoking behavior among college students following implementation of a strict campus smoking policy in Taiwan. Int J Public Health 57(1):199-205. doi:10.1007/s00038-011-0265-5

Federal Office for the Environment FOEN (2013). 7. Air Quality. In: Environment Switzerland 2013. Chapter II: State of the Environment. http://www.bafu.admin.ch/publikationen/publikation/ 01722/index.html?lang=en. Accessed 16 Sept 2013

Friedrich V, Brugger A, Bauer G (2009) Worksite tobacco prevention in the Canton of Zurich: stages of change, predictors, and outcomes. Int J Public Health 54(6):427-438. doi:10.1007/ s00038-009-0084-0

Fromme H, Kuhn J, Bolte G (2009) Secondhand smoke in hospitality venues. Exposure, body burden, economic and health aspects in conjunction with smoking bans. Gesundheitswesen 71(4): 242-257. doi:10.1055/s-0029-1192031

Halpern MT, Taylor H (2009) Beliefs regarding smoking in the workplace: results from the Global Workplace Smoking Survey. Int J Public Health 54(6):391-401. doi:10.1007/s00038-0090086-y

Hauri DD, Lieb CM, Rajkumar S, Kooijman C, Sommer HL, Röösli M (2011) Direct health costs of environmental tobacco smoke exposure and indirect health benefits due to smoking ban introduction. Eur J Public Health 21(3):316-322. doi:10.1093/ eurpub/ckq142

Huss A, Kooijman C, Breuer M, Böhler P, Zünd T et al (2010) Fine particulate matter measurements in Swiss restaurants, cafes and bars: what is the effect of spatial separation between smoking and non-smoking areas? Indoor Air 20(1):52-60. doi:10.1111/j. 1600-0668.2009.00625.x

Hyland A, Higbee C, Borland R, Travers M, Hastings G et al (2009) Attitudes and beliefs about secondhand smoke and smoke-free policies in four countries: findings from the International Tobacco Control Four Country Survey. Nicotine Tob Res 11(6):642-649. doi:10.1093/ntr/ntp063

Krebs H (2011). Exposure to second-hand smoke in the Swiss Population in 2010. Factsheet of the research report 2011. http:// www.tabakmonitoring.ch/Berichte/Factsheets/factsheet_passiv_ 10_en.pdf. Accessed 16 Sept 2013

Lazuras L, Zlatev M, Rodafinos A, Eiser JR (2012) Smokers' compliance with smoke-free policies, and non-smokers' assertiveness for smoke-free air in the workplace: a study from the Balkans. Int J Public Health 57(5):769-775. doi:10.1007/ s00038-012-0338-0

Lopez MJ (2010) The Spanish smoking law: a model to be followed? Int J Public Health 55(3):231-232. doi:10.1007/s00038-010$0129-4$

Moore K, Borland R, Yong H-H, Siahpush M, Kummings KM et al (2012) Support for tobacco control interventions: do country of origin and socioeconomic status make a difference? Int J Public Health 57(5):777-786. doi:10.1007/s00038-012-0378-5

Pope CA III, Burnett RT C, Turner MC, Cohen A, Krewski D (2011) Lung cancer and cardiovascular disease mortality associated with ambient air pollution and cigarette smoke: shape of the exposure-response relationships. Environ Health Persp 119(11): 1616-1621. doi:10.1289/ehp.1103639

Rajkumar S, Huynh CK, Bauer GF, Hoffmann S, Röösli M (2013) Impact of a smoking ban in hospitality venues on second hand smoke exposure: a comparison of exposure assessment methods. BMC Public Health 13:536. doi:10.1186/1471-2458-13-536

Röösli M (2011) Non-cancer effects of chemical agents on children's health. Prog Biophys Mol Biol 107(3):315-322. doi:10.1016/j. pbiomolbio.2011.08.006

Schikowski T, Schaffner E, Meier F, Phuleria HC, Vierkötter A et al (2013) Improved air quality and attenuated lung function decline: modification by obesity in the SAPALDIA cohort. Environ Health Persp 121(9):1034-1039. doi:10.1289/ehp. 1206145

Schulz PJ, Hartung U, Fiordelli M (2012) Effect of smoke-free legislation on Ticino gastronomy revenue. Int J Public Health 57(6):861-866. doi:10.1007/s00038-012-0402-9

Sommer H, Lieb C, Van Nieuwkoop R, Maibach M, Schreyer C et al (2008) Externe Kosten des Verkehrs in der Schweiz Aktualisierung für das Jahr 2005 mit Bandbreiten. http://opus.kobv.de/zlb/ volltexte/2008/6523/). Accessed 16 Sept 2013

U.S. Department of Health and Human Services (2006) The health consequences of involuntary exposure to tobacco smoke-a report of the surgeon general. U.S. Department of Health and Human Services, Centers for Disease Control and Prevention, Coordinating Center for Health Promotion, National Center for Chronic Disease Prevention and Health Promotion, Office on Smoking and Health, Atlanta

Usmanova G, Mokdad AH (2013) Results of the global youth tobacco survey and implementation of WHO Framework convention on tobacco control in former Soviet Union countries. Int J Public Health 58(2):217-226. doi:10.1007/s00038-012-0433-2 